\title{
CREATIVE TRANSFER IN THE ENGINEERING CLASSROOM
}

\author{
Ken Tallman and Christina Mei \\ University of Toronto \\ k.tallman@utoronto.ca; christina.mei@mail.utoronto.ca
}

\begin{abstract}
This research on creativity in undergraduate engineering education asks whether undergraduate engineering students in a Fall 2016 course will develop enriched creative skills in other learning and professional environments as a result of having taken the course. The motivation for this study comes from the need for a clearer understanding of how and where to teach creativity in the undergraduate curriculum and a clearer understanding of how students transfer skills and knowledge from one setting to another. As well as studying students' creative growth, the research will analyze students' metacognitive development. What do students learn about how they learn by taking this course? Is this knowledge valuable? Are students able to better articulate their creative processes once they have finished the course? Have they found ways to make use of this advanced knowledge? The results from this research are preliminary and inconclusive, but appear promising. Research data at present consists primarily of audiorecorded interviews with consenting students, and more data is likely required to provide better certainty about whether students have been able to transfer their creative activity from this course to other situations.
\end{abstract}

\section{Keywords: Creativity, Engineering, Education, Art}

\section{LITERATURE REVIEW}

In the twentieth and twenty-first centuries, the most fruitful research on creativity has come from the field of psychology. In the 1960s Abraham Maslow proposed "self-actualizing" (SA) creativity, a tool available to all people, freeing us from the myth that only a special few had access to this gift [5]. Mihaly Csikszentmihalyi, in 1996, connected creativity to culture and society, explaining it as a process by which a "symbolic domain in the culture is changed" [1]. Writing a song or building a machine, he says, is only creative if it changes how we understand songs or machines. He also notes that "centers" of creativity tend to be at the "intersection" of different cultures, permitting individuals to "see new combinations of ideas with greater ease" [1].
Understanding creativity in relation to "intersections" has precedence. Einstein, late in his life, in 1954, observed that "Taken from a psychological viewpoint, this combinatory play seems to be the essential feature in productive thought" [2]. The mathematician, physicist, and engineer Henri Poincaré made this point in the 1920s when reflecting on his own creative process: "To create consists of making new combinations of associative elements that are useful" [7]. Furthering this connection between creativity and association, Sarnoff Mednick, in the early 1960s, asserted that creativity is associative memory put into action. His Remote Association Test (RAT), built on word association, is still regularly used in studies of creativity [6].

More recently, in 2012, Daniel Kahneman linked creativity to intuition, explaining it as an automatic and effortless force [3]. Dean Keith Simonton, in 2004, following a similar path, drew attention to the primary role that chance plays in scientific creativity and discovery [11], but Albert Rothenberg, in 2015, challenges this, stressing that the motivation to create is a conscious factor, and that the goal is to "look for or produce something new." [8] Echoing Arthur Koestler, Rothenberg explains creativity as a Janusian process, one built on patterns of opposition and paradox $[4,8]$.

\section{COURSE BACKGROUND}

I conceived and first taught APS325: Engineering and Science in the Arts in Fall 2012. Offered as a Humanities Social Science elective course to undergraduate engineering students, the course provides students the opportunity to expand their creative practices in a new but familiar context. In the course, students create original works of art that are connected to engineering and/or science and present these works to the class at the end of term. As well, students take two or three field trips to galleries or live performances, critiquing these in relation to principles from engineering, science, and art theory, and, finally, students make seminar presentations on artists or artistic movements of their choice, once again connecting these to engineering or science. 


\section{RESEARCH PROCEDURE}

Seven students from the class of 19 volunteered to participate in this research project. I informed students that their participation would involve a one-hour interview to be scheduled in late April, 2017, a full term after the course had ended, in December, 2016.

For the audio-recorded interviews, Christina Mei, my research assistant, and I assembled a set of questions aimed to determine if the students had been able to use any of the skills or knowledge from APS325 in other learning or professional environments. We focused our questions on journals that the students kept in the course and on course assignments, notably field trip critiques and the final work of art each student created, accompanied by a final written report and slide presentation. We also asked the participants questions about how APS325 may have affected their experiences in other courses or professional settings.

The interviews were, thus, semi-structured, giving each student the opportunity to go in his or her direction as discussion developed. Included here are the set questions we asked each student:

1. What is your current understanding of the term "creativity"?

2. Did your understanding of creativity change during the course? If so, how? Is there evidence of this?

3. Have you been able to use this new understanding of creativity anywhere else since taking the course?

4. Did the course give you any new approaches or new knowledge that you can take with you to new situations?

5. Did this course affect your experience in your capstone design course? [For $4^{\text {th }}$ year students]

6. Overall, did this course teach you anything about how you learn?

7. Which creative activities in the course could be improved?

\section{INTERVIEW RESULTS}

As mentioned, seven students volunteered to participate in the research project interview. We scheduled the interviews with six of the students in the last week of April, 2017, and we scheduled one interview earlier in January, 2017, at the student's request. We wanted to wait as long as possible after the course had ended to conduct the interviews, hoping that students would find opportunities to make use of APS325 in other settings. However, we didn't want to wait beyond the end of the April 2017 exam period, as many students would have left for the summer, or, having graduated, would have left Toronto permanently.
Our analysis of the interviews is still at a preliminary stage and will benefit from closer study over time. We have, however, discovered some notable patterns that help us better understand what students have taken with them from the course, and how we, as instructors, can make use of these learning transfers and student takeaways.

In regard to creative activity connected with the course, all seven students interviewed pointed us, in varying degrees of detail, to the following threads: 1) Collaboration; 2) Interdisciplinary thinking; 3) Scope and Complexity; 4) Process; 5) Transfer. Taking each in turn, we will discuss how students and instructors can use these threads to enrich creative activity in their learning environments.

\subsection{Collaboration}

Student A noted the unique teamwork in APS325. Students regularly meet in groups during class time to provide feedback on their projects or to critique readings or works of art. There are, however, no defined or permanent groups. This transience and flexibility, according to Student A, allowed her to take feedback more openly than she might had she worked with the same team members all term. She noted that the learning environment was very supportive and encouraging. "I was not forced to learn."

Student C noted that students learn from each other. Given the regular opportunity to provide constructive feedback, Student $\mathrm{C}$ felt he improved his ability to provide others with valuable insights. Student E echoed this, saying, "I am more willing to accept the diversity, more open minded and willing to listen to others." Finally, Student G claimed that the course environment encouraged a "matching quality," noting that the frequent small group discussions and critiques motivated him to raise the quality of his work: "I felt like my work needs to be as good as others."

Instructors might consider the value of creating ad hoc student groups on a regular basis. As the statements above suggest, students value the freedom that this transience allows. In permanent teams, students perhaps feel the weight of obligation and accountability - weights that are certainly important but perhaps not always the best fit. As well, instructors might note the students' positive response to choosing to contribute, rather than being forced: they appreciated being able to decide themselves how to join in with class activities.

Collaboration is certainly practiced in many of our undergraduate courses, and APS325 shows but one way it can be used to generate creative activity.

\subsection{Interdisciplinary thinking}

Students taking APS325 come from all undergraduate engineering streams and are most often in their third or 
fourth year of study. Many have already taken their Professional Experience Year (PEY) and come to the class with this enriched and enriching perspective.

In her interview, Student A noted that discussion with students from different engineering streams encouraged creativity. This is perhaps consistent with Csikszentmihalyi's contention that creativity occurs at the "intersection" of different cultures [1]. Divergent thinking opens new doors.

As well as opening discussion between different engineering streams, APS325 encourages students to open channels between different fields - engineering, science, and the arts. A few students emphasized the creative benefit in building these connections. Student B noted that he was able to practice "lateral thinking" - relating different things that seemed to be unrelated. Student D noted that her final project benefitted from looking at projects from different angles, not only from an engineering perspective. Student F and Student $G$ both agreed that learning from peers with different engineering backgrounds provided breadth and unexpected insight.

In many core courses, we are not able to bring students from different streams together, although opportunities for this are certainly increasing. We can, however, strive to introduce our students to divergent thinking and divergent perspectives as we build our curricula. Recognizing that students appreciate being directed toward cultural and intellectual intersections should help us make productive choices in our course planning.

\subsection{Complexity and Scope}

At the beginning of her interview, Student A stated that in APS325 she learned to become comfortable with ambiguity: "I had to think more openly. The more I pushed myself, the more creative I could be." In fact, most of the students participating in this study stated that they came away from the course with a higher level of open thinking, resulting in an enhanced appreciation for non-representational forms of expression. Student A and Student B claimed that they entered the course with a mistrust for abstract art, and Student D said she came into the course skeptical of the value of art in general and of abstract art in particular. After completing the course, however, all admitted to seeing the abstract as especially interesting and stimulating. In keeping, perhaps, with Maslow's contention that "self-actualizing" (SA) creative types can be "comfortably disorderly ... chaotic ... uncertain" [5], these students saw this shift in themselves as a welcome transformation.

On the other side, some students emphasized the value of constraints. Because the course requires students to work through the entire design experience, from conception to completion, it is important, as Student B put it, "to determine the scope and scale of the project." Student G went further, stating that "some constraints helped with creativity." Student D echoed this: "The need for boundaries is critical," and Student F reinforced this point: "Creativity comes with more constraints. Constraints are required to push me to think harder." Though some constraints came from me, these were mainly had to do with assignment length and presentation schedules. The substantive constraints came from the students themselves and from their classmates.

Instructors might consider two things here: first, students may be reluctant to accept complexity and disorder, or may have a bias against them; upper-year students, however, proved that with some prompting they were quickly able to abandon these prejudices and to embrace the uncertainty of abstract forms of representation. Secondly, students value constraints, particularly those that they themselves discover.

\subsection{Process}

In the interviews, students drew attention to the importance of tracking their creative processes during the course. All students commented on the value of keeping a journal. Student A claimed that writing down small ideas "will eventually develop into a design process." Student B said the journal played an important part in the creative process, as he could "iterate on the ideas" before developing them in his project. Student C likewise saw the value in the journal: "The journal helped me rule out things, record what was successful or not."

Students noted that because the course asks them to reflect on their creative process, they became, overall, more cognizant of themselves. Student C said, "The course taught me to be more observant, which I believe is critical in the creative process." Student F attributed this metacognitive awareness of his creative process to his open-mindedness: "From this course I learned it is important to be more open-minded; design doesn't have to be systematic."

Finally, when shown Simonton's four models for creativity (logic, genius, chance, zeitgeist) [11], students most often saw chance as playing the lead role among the four in their own projects. Student $C$ and $G$ claimed that the final project started with chance and then was led by logic; Student F, on the other hand, saw logic leading to a chance outcome.

Instructors may feel reassured that students do value tracking their working processes and reflecting on them. The journals were graded ( $10 \%$ of the course mark), so students did feel obligated to keep them, but the overall high quality of the journals indicated the students saw intrinsic value in keeping this record. Finally, instructors may be interested to see how highly students value chance in the creative process. This valuation came as a surprise to most students who initially believed logic would be the prevailing force in creative activity. 


\subsection{Transfer}

In the interviews, most students had to be prompted to consider ways they have transferred their creative activity from APS325 to other settings. Student A was quick to see the experimental nature of her art work in APS325, but it took some prompting for her to recognize how this matched the approach she takes in her engineering work. Similarly, Student B noted the "free exploration" of his approach to his engineering capstone project, but, again, it took time in the interview for him to connect this to the open approach he took to his final project in APS325. Student $\mathrm{C}$ saw the benefits of having an open mind in his engineering work, something that wasn't clear to him before taking the course, but he couldn't yet find a time or place he had yet been able to use this knowledge since AS325 had concluded. Finally, Student D claimed she had learned the value of multiple perspectives in APS325 (in particular through Cubist art) and that she had put this insight into practice in her engineering capstone successfully. Like the other students, however, she discovered this connection in the interview. It was not something she had thought about previously.

Both Christina, my assistant, and I recognized that the students we interviewed were able to connect APS325 to other learning and professional settings but were able to do so only when prompted. This suggested three things: 1) Connecting and integrating learning experiences is not something that comes easily for undergraduate students; 2) The interview setting is a natural place to encourage this type of connection and integration; 3) The interviews may have been more beneficial if scheduled after more time had passed since the course concluded

\section{CONCLUDING REMARKS}

The value of this study is only partially clear in this account. If this study aims to determine whether students will develop enriched creative skills in other learning and professional environments as a result of having taken APS325, the answer is uncertain. The initial signs are promising, as evident from the student interviews, but a more developed research approach will probably be required to find firmer answers. The clearest path, in this regard, would be to meet again with the participating students in the future, perhaps a year from now. Meeting with the students, as we did, a matter of four months after the course ended, brought predictably limited responses.

\section{References}

[1] Mihaly Csikszentmihalyi, Creativity: Flow and the Psychology of Discovery and Invention, New York, HarperCollins, 1996.
[2] Albert Einstein, Ideas and Opinions, Trans. S. Bargmann, New York, Modern Library, 1954.

[3] Daniel Kahneman, Thinking Fast and Slow, London, UK, Penguin, 2011.

[4] Arthur Koestler, "Bisociation in Creation," in The Creativity Question, Ed. Albert Rothenberg and Carl R. Hausman, Durham, N.C., 1976, pp. 108-113.

[5] Abraham H. Maslow, "Creativity in Self-Actualizing People," in The Creativity Question, Ed. Albert Rothenberg and Carl R. Hausman, Durham, N.C., 1976, pp. 311-326.

[6] Sarnoff A. Mednick, "The associative basis of the creative process," Psychological Review, vol. 69, no. 3, 1962, pp. 220-232.

[7] Henri Poincaré, The Foundations of Science, Science and Hypothesis, The Value of Science, Science and Method, Trans. G.B. Halstead, New York, N.Y., Science Press, 1921.

[8] Albert Rothenberg, "The Process of Janusian Thinking in Creativity," in The Creativity Question, Ed. Albert Rothenberg and Carl R. Hausman, Durham, N.C., 1976, pp. 311-326.

[9] Albert Rothenberg, Flight from Wonder: An Investigation of Scientific Creativity, New York, Oxford University Press, 2015.

[10] Herbert A. Simon, "Does scientific discovery have a logic?" Philosophy of Science, vol. 40, no. 4, 1973, pp. 471480 .

[11] Dean Keith Simonton, Creativity in Science: Chance, Logic, Genius, and Zeitgeist. New York and Cambridge: Cambridge University Press, 2004. 